\title{
Экспертиза
}

КАЗАКОВА Ноила Дохиевна - доктор социологических наук, профессор кафедры организационно-кадровой работы в органах государственной власти Института экономики и права МИРЭА - Российского технологического университета (107996, Россия, г. Москва, ул. Стромынка, 20; kazaknelli@yandex.ru)

ДЕНИСОВА Жанна Александровна - кандидат социологических наук, доцент кафедры организационно-кадровой работы в органах государственной власти Института экономики и права МИРЭА - Российского технологического университета (107996, Россия, г. Москва, ул. Стромынка, 20; denisova@yandex.ru)

\section{КАДРОВЫЕ РИСКИ В УПРАВЛЕНИИ ПЕРСОНАЛОМ ГОСУДАРСТВЕННОЙ ГРАЖДАНСКОЙ СЛУЖБЫ}

Аннотация. В статье проведен анализ различных определений понятия «кадровый риск», показаны их недостатки. Предложено авторское определение кадрового риска в управлении персоналом государственной гражданской службы. Автор обосновывает, что некорректно связывать кадровые риски в управлении персоналом гражданской службы только с неправомерным поведением гражданских служащих; в их реализации активно участвуют (или, напротив, бездействуют) и другие категории персонала органа государственной власти.

Ключевые слова: кадровые риски, управление персоналом государственной гражданской службы, категории персонала органа государственной власти

$\mathrm{P}$ иски являются неотъемлемой частью жизни современного общества, постоянно сопровождая жизнедеятельность личности и социумов различного уровня. Этот факт нашел свое отражение в возросшем интересе науки к этому феномену, проведении исследований учеными и научными центрами, формировании академических дисциплин, во внедрении риск-менеджмента в структуру управления корпорациями и органами государственной власти.

Не остались в стороне от изучения рисков и ученые, занимающиеся вопросами государственного управления и государственной службы, хотя предметом исследований в данных сферах выступают преимущественно коррупционные риски, активно изучаемые научным сообществом различных областей знания. Следует также отметить большое число публикаций о кадровых рисках в управлении персоналом организации, тогда как кадровые риски в управлении персоналом государственной гражданской службы и органов государственной власти являются недостаточно исследованными. Здесь можно отметить публикации С.В. Духновского, в которых акцент делается на психологической надежности гражданских служащих, рассматриваемой в качестве условия, снижающего кадровые риски [Духновский 2018], труды А.Ю. Долинина о кадровых рисках учреждений и органов уголовно-исполнительной системы [Долинин 2017], а также статью, в которой представлены результаты исследования о конфликтологическом консультировании как методе минимизации кадровых рисков в работе с персоналом таможенных органов [Калмыкова и др. 2017].

Приведем несколько определений понятия «кадровый риск», сформулированных известными российскими специалистами в этой области научного знания. Это:

- «потенциальные потери или угрозы финансово-хозяйственной деятельности предприятия, связанные с деятельностью собственного персонала предприятия» [Капустина 2008: 139]; 
- «вероятности нанесения предприятию материального или морального ущерба в процессе принятия и реализации кадровых решений» [Слободской 2011: 67];

- «риски, связанные с вероятностью реализации угроз, исходящих от персонала...Учитывая, что персонал опосредует все стороны экономических отношений в организации, можно определить кадровые риски как комплексные, важнейшими из которых являются риски утраты конфиденциальной информации, коммерческие риски» [Потемкин, Копейкин 2012: 17];

- «отклонение от намеченных целей или снижение ожидаемого эффекта от запланированного, которое происходит в результате любого действия или бездействия члена коллектива работников предприятия, объединенных в процессе производства» [Цветкова, Ботенко 2016: 257];

- «ситуация, отражающая меру реальности нежелательного развития событий, которые напрямую или косвенно затрагивают функционирование и развитие организации, персонала, общества в целом и наступление которых связано с объективно существующей неопределенностью, обусловленной рядом причин: неэффективностью системы управления персоналом; поведением, действием (бездействием) персонала; внешней средой организации» [Митрофанова 2013: 11-12].

В приведенных дефинициях акцент делается на то, что кадровый риск для организации представляет угрозу, опасность, приносит ущерб, вызывает неблагоприятные события, снижает ожидаемый эффект и т.д. То есть, не используется вариант рассмотрения риска как некоторой возможности, которая может иметь и позитивные последствия. Именно такой подход правомерно применять при трактовке кадровых рисков в управлении персоналом государственной гражданской службы.

Вместе с тем Н.В. Капустина ограничивает угрозы кадровых рисков только областью финансово-хозяйственной деятельности предприятия. Очевидно, недостаточно и связывать кадровые риски только с принятием и реализацией кадровых решений, как это делает А.Л. Слободской.

Уточнение В.К. Потемкина и Г.К. Копейкина к основному определению, касающееся опосредования персоналом только экономических отношений в организации, сужает спектр организационных отношений, а выделение в качестве важнейших кадровых рисков утрату конфиденциальной информации и коммерческие риски априори ограничивает их многообразие. Надо полагать, что не любое действие члена коллектива может привести к отклонению от намеченных целей или снижению ожидаемого эффекта от запланированного, как утверждается в определении И.И. Цветковой, а только способствовать реализации риска.

Риск - не ситуация, отражающая меру реальности нежелательного развития событий, как считает А.Е. Митрофанова, а вероятность неблагоприятного события. Неэффективность управления персоналом и действие (бездействие) персонала не являются причинами объективно существующей неопределенности, поскольку они вполне диагностируемы и контролируемы - иначе управление кадровыми рисками не имело бы смысла. Другое дело - внешняя среда организации любого типа, преподносящая постоянные «сюрпризы» для акторов экономической, политической, социокультурной и в целом общественной жизни.

Что касается трактовок кадрового риска в государственной службе и органах государственной власти, то, например, С.В. Духновский полагает, что «это возможная опасность государственного гражданского служащего для организации, обусловленная его индивидуально-психологическими (глу- 
бинно-психологическими) особенностями личности» [Духновский 2018: 149]. Помимо того что автор оперирует термином «организация», распространяя свое определение на все типы организаций, игнорируя то, что государственные гражданские служащие трудятся только в органах государственной власти, имеющих ярко выраженную специфику, выделение в качестве причин кадровых рисков лишь индивидуально-психологические особенности личности гражданского служашего является недостаточным. Хотя в дальнейших пояснениях к своему определению он связывает проявление кадровых рисков с рассогласованием между общей стратегией управления организацией, социально-кадровой политикой и их субъективной оценкой сотрудниками, тем не менее он уточняет, что оценки сотрудников обусловлены «регулятивными, индивидуально-типологическими и профессионально-психологическими особенностями надежности государственных гражданских и муниципальных служащих» [Духновский 2018: 149].

А.Ю. Долинин использует в своих работах следующее определение: «Под кадровыми рисками учреждений и органов УИС следует понимать вероятность снижения эффективности уголовно-исполнительной практики, обусловленную неполной реализацией служебного потенциала сотрудников и их неправомерным служебным поведением вследствие нерационального использования кадрового потенциала ФСИН России» [Долинин 2017: 57]. Здесь нерациональное использование кадрового потенциала ФСИН России рассматривается как первоисточник кадровых рисков органов и учреждений УИС, и, по сути дела, ответственность за их реализацию переносится на систему более высокого порядка. Вместе с тем словосочетание «неправомерное служебное поведение сотрудников» как причина кадровых рисков может быть использовано в определении кадровых рисков всех видов государственной службы и ветвей государственной власти.

В качестве лишь «проблем неэффективного использования человеческих ресурсов (кадровых рисков в управлении персоналом)» позиционируют кадровые риски О.Ю. Калмыкова и ее соавторы [Калмыкова и др. 2017].

С учетом вышеизложенного предлагаем следующее определение: кадровый риск в управлении персоналом государственной гражданской службы - это вероятность неблагоприятного события, связанного с решениями, действием (бездействием), неправомерным поведением должностных лиц, персонала, влиянием внешней среды и представляющего угрозу негативного воздействия на обеспечение государственными гражданскими служащими исполнения полномочий органа государственной власти по организации и регулированию общественных отношений, решению задач по реализации интересов личности, государства и общества.

При исследовании кадровых рисков в управлении персоналом государственной гражданской службы необходимо учитывать следующий важный аспект. В общую численность занятых в государственных органах Росстат включает следующие категории персонала1:

1) государственные должности;

2) должности государственной гражданской службы;

3) должности иного вида федеральной государственной службы (сотрудники, имеющие специальные звания);

4) другой персонал (работники, обеспечивающие деятельность гражданских служащих, а также персонал по охране и обслуживанию зданий).

Лица, занимающие государственные должности, государственными служа-

\footnotetext{
1 Данные об общей численности работников, занятых в государственных органах, органах местного самоуправления и избирательных комиссиях муниципальных образований. Доступ: http://www.gks.ru/ free_doc/new_site/gosudar/met_ochi3.htm (проверено 07.11.2018).
} 
щими не являются, их деятельность регулируется Конституцией РФ, конституциями и уставами субъектов РФ, указами Президента РФ. Государственные должности не относятся к должностям государственной службы, а лица, их замещающие, непосредственно исполняют полномочия органов государственной власти.

Персонал государственной гражданской службы - это совокупность лиц, занимающих должности государственной гражданской службы, имеющих особый социально-правовой статус и обеспечивающих исполнение полномочий органов государственной власти Российской Федерации и ее субъектов, а также лиц, замещающих государственные должности в этих органах. Деятельность этой категории персонала строго регламентирована ввиду высокой ее значимости, законодательно закреплены права, обязанности, особые гарантии, запреты и ограничения.

Лица, занимающие должности иного вида федеральной государственной службы, не являются гражданскими служащими: их деятельность регулируется специальными законами о соответствующем виде государственной службы (правоохранительной, противопожарной, гражданской обороны, защиты от чрезвычайных ситуаций и т.д.).

Кадры четвертой категории не являются государственными служащими, их деятельность регулируется Трудовым кодексом РФ, а организация труда прописана в специальных нормативных правовых актах органа государственной власти. Их социально-правовой статус не предполагает специальных гарантий, запретов и ограничений, как в случае с государственной службой.

Лица, замещающие государственные должности, несмотря на свою малочисленность, выступают в качестве субъектов управления как органов государственной власти, так и управления персоналом, оказывая непосредственное воздействие на поведение и деятельность гражданских служащих и других категорий персонала. Именно на них лежит ответственность за создание условий, способствующих или, напротив, препятствующих реализации кадровых рисков в органе государственной власти. Более того, кадровые решения, действие или бездействие, неправомерное поведение и в целом отношение к персоналу этих лиц напрямую выступают источниками кадровых рисков.

Поэтому некорректно связывать кадровые риски в управлении персоналом гражданской службы только с неправомерным поведением гражданских служащих - в их реализации активно участвуют (или, напротив, бездействуют) также руководители органов государственной власти как на государственных должностях, так и должностях государственной гражданской службы и другие категории персонала.

Традиционно риски, в частности коррупционные, в сфере государственного управления связываются только с государственными служащими, тогда как в их реализации могут участвовать и иные должностные лица. Очевидно, не случайно в 2016 г. из выявленных прокурорами 2,5 тыс. нарушений антикоррупционного законодательства, связанных с неурегулированием конфликта интересов, 728 лиц привлечены к дисциплинарной ответственности, в т.ч. 56 государственных, муниципальных служащих и иных должностных лиц уволены в связи с утратой доверия. В этом же году за нарушения, связанные с неурегулированием конфликта интересов, по представлениям прокуроров к дисциплинарной ответственности привлечены служащие федерального уровня (25\%), служащие уровня субъекта РФ (6\%), служащие муниципального уровня 
$(35 \%)$, иные должностные лица $(34 \%)^{1}$. То есть, в этих нарушениях, помимо государственных служащих, задействована значительная доля и иных должностных лиц, под которыми Генеральной прокуратурой РФ в рамках применения ст. 19.28 КоАП РФ понимаются лица, «временно или по специальному полномочию осуществляющие функции представителя власти либо выполняющие организационно-распорядительные, административно-хозяйственные функции в государственных органах, органах местного самоуправления, государственных и муниципальных учреждениях, государственных корпорациях, а также в Вооруженных Силах РФ, других войсках и воинских формированиях Российской Федерации. В эту категорию входят также лица, замещающие государственные должности Российской Федерации и государственные должности субъектов Российской Федерации» ${ }^{2}$.

Добавим к вышеизложенному, что численность работников, замещавших должности гражданской службы в федеральных государственных органах, на конец декабря 2017 г. составила 38,3 тыс. чел., или 77,0\% общей численности работников этих органов ${ }^{3}$. В государственных органах РФ на региональном уровне (в федеральных государственных органах и государственных органах субъектов РФ) в 2017 г. замещали должности государственной гражданской службы 696,7 тыс. чел., или 42,2\% общей численности работников, занятых в этих органах 4 .

Однако выбор кадровых рисков в управлении персоналом гражданской службы в качестве предмета исследования представляет научный и практический интерес, во-первых, вследствие высокой значимости этой категории персонала в обеспечении исполнения полномочий органов государственной власти. Именно гражданские служащие выполняют незаменимую роль и имеют преимущества перед лицами, занимающими государственные должности, при подготовке, принятии и исполнении государственных решений, поскольку обладают детальными «техническими знаниями, специализируются по конкретным сферам жизнедеятельности общества, регулярно проходят через систему обучения и оценки профессиональных качеств, осуществляют свою деятельность более длительный период, не тратят времени на избирательные кампании и т.д.» [Граждан 2007: 87-88].

Во-вторых, у государственных гражданских служащих низок уровень неопределенности в деятельности, поскольку вследствие строгой ее регламентации они точно знают:

а) каким должно быть их служебное поведение, т.к. оно имеет ограниченный набор альтернатив действий в ситуациях риска в отличие, например, от наемных работников организаций коммерческого сектора;

б) какие санкции последуют за неправомерные рисковые действия, нарушающие законодательные нормы об обязанностях, запретах и ограничениях.

Об этом свидетельствуют результаты экспертного опроса, проведенного сотрудниками РАНХиГС с ноября 2016 по февраль 2017 г. Эксперты считают,

1 Методика Генеральной прокуратуры РФ «Конфликт интересов на государственной и муниципальной службе. Памятка для служащих». Доступ: http://www.garant.ru/products/ipo/prime/ doc/71564038/\#ixzz5SgwNYBAq (проверено 04.10.2018).

2 Прокурорский надзор за исполнением законодательства о противодействии коррупции: сборник методических рекомендаций (под общ. ред. А.Е. Русецкого). М. 2017. С. 61.

3 о численности и оплате труда гражданских служащих федеральных государственных органов (центральных аппаратов министерств и ведомств) за 2017 год. Доступ: http://www.gks.ru/bgd/free/ B04_03/IssWWW.exe/Stg/d03/plat2.htm (проверено 02.10.2018).

$4^{-}$О численности и оплате труда государственных гражданских и муниципальных служащих на региональном уровне за 2017 год. Доступ: http://www.gks.ru/bgd/free/b04_03/IssWWW.exe/Stg/d03/56. htm (проверено 02.10.2018). 
что в своей деятельности гражданские служащие при выполнении должностных обязанностей руководствуются преимущественно должностными регламентами (50,7\% выбора экспертов), указаниями непосредственного руководителя и частично - должностными регламентами $(68,6 \%)$ и интересами своего государственного органа $(30,7 \%)$. Это, казалось бы, должно обусловить исключение любых неправомерных действий государственных гражданских служащих. Однако, по мнению экспертов, хотя и в меньшей степени, они также руководствуются собственными представлениями о том, что следует выполнять, а что - нет $(21,4 \%)$, личной ответственностью за порученное дело $(17,1 \%)$, сугубо личными интересами $(13,6 \%)$, следуют только указаниям непосредственного руководителя $(12,9 \%)$. При этом эксперты указывают на преобладание низкой (19\%) и средней $(57,7 \%)$ степени выраженности уважения к законам, низкой $(47 \%)$ и средней $(43,7 \%)$ степени выраженности чувства служения государству и обществу, низкой $(57 \%)$ и средней $(33,8 \%)$ степени выраженности бескорыстия и почти такого же порядка степени выраженности ответственности за дело, справедливости, честности и принципиальности [Магомедов 2017: 24, 29]. В совокупности данные экспертного опроса показывают, что регламентированность деятельности гражданских служащих не исключает оснований для реализации кадровых рисков. Классификация и выявление причин (факторов и условий) кадровых рисков в управлении персоналом государственных гражданских служащих, а также принятие и реализация адекватных мер реагирования позволят их минимизировать.

В-третьих, публично-властный характер деятельности государственных гражданских служащих делает их объектом пристального внимания со стороны общественности, СМИ, правозащитных организаций и т.д. Это приводит к тому, что по поведению гражданских служащих население оценивает эффективность деятельности как органов государственной власти, так и государственного управления в целом. Между тем, согласно результатам социологического опроса, проведенного сотрудниками РАНХиГС с октября 2016 по март 2017 г., авторитет государственных служащих оценили как высокий лишь 6,7\% респондентов, как средний $-45,3 \%$, как низкий $-44,6 \%$, затруднились ответить $-3,4 \%$. В качестве причин этого $34,7 \%$ опрошенных отметили слабую профессиональную подготовку; 40,4\% - низкие нравственные качества; 27,1\% низкий уровень гражданственности; 30,6\% - пренебрежение к законам; 65,9\% - коррумпированность, взяточничество; 47,1\% - бюрократизм, 16,1\% - низкий авторитет государства в целом; 50,7\% - оторванность от интересов граждан [Магомедов 2017: 12] ${ }^{1}$.

Поэтому проблема кадровых рисков в управлении персоналом государственной гражданской службы является актуальной и требует научного исследования.

Необходимо подчеркнуть и тот факт, что коррупционные риски следует позиционировать как вид кадровых рисков, потому что как понятие и явление кадровые риски шире, чем коррупционные риски, поскольку последние - «это заложенные в системе государственного и муниципального управления возможности для действия/бездействия должностных лиц с целью незаконного извлечения материальной и иной выгоды при выполнении своих должностных полномочий и наносящие ущерб государственным и общественным интересам» [Дементьева 2012: 77].

Помимо конфликта интересов и коррупции, в структуру кадровых рисков входят риски непрофессионализма, низкого качества труда, нарушений слу-

\footnotetext{
1 Можно было выбрать несколько вариантов ответов.
} 
жебной дисциплины, халатности, безответственности, демотивации, дезадаптации, профессионального «выгорания» и т.д., которые не связаны с извлечением выгоды.

Однако игнорирование многообразия этих видов кадровых рисков приводит к тому, что они с большой степенью вероятности могут трансформироваться в коррупционные риски.

Этот процесс идентичен развитию системного внутреннего кризиса в государственных учреждениях, описанного С.В. Любичанковским, когда сотрудник вначале халатно, незаинтересованно относится к выполнению своих обязанностей, затем злоупотребляет своим служебным положением и, наконец, входит в устойчивое неформальное объединение с другими сотрудниками с целью охраны, защиты и расширения своих возможностей по удовлетворению личных потребностей за счет государственных интересов [Любичанковский 2008: 57].

Помимо того что кадровые риски представляют угрозу для выполнения государственными гражданскими служащими и органами государственной власти своего предназначения в государственном управлении, если не управлять ими, они достигают высокой степени опасности для реализации интересов личности, государства и общества.

\section{Список литературы}

Граждан В.Д. 2007. Государственная гражданская служба: учебник. 2-е изд., перераб. и доп. М.: КНОРУС. 496 с.

Дементьева И.Н. 2012. Исследование коррупционных рисков в региональных органах государственной власти. - Проблемы развития территории. № 2. C. 75-85.

Долинин А.Ю. 2017. Кадровые риски учреждений и органов уголовно-исполнительной системы. - Уголовно-исполнительное право. Т. 12. № 1. С. 56-61.

Духновский С.В. 2018. Оценка психологической надежности государственных гражданских служащих: проблемы и перспективы. - Институт психологии Российской академии наук. Организационная психология и психология труда. Т. 3. № 2. C. 140-165.

Калмыкова О.Ю., Трубицын К.В., Хрящев В.В., Ткачев В.К. 2017. Конфликтологическое консультирование как метод минимизации кадровых рисков в работе с персоналом таможенных органов. - Науковедение: интернет-журнал. Т. 9. № 1(38). Доступ: https://cyberleninka.ru/article/n/ konfliktologicheskoe-konsultirovanie-kak-metod-minimizatsii-kadrovyh-riskov-vrabote-s-personalom-tamozhennyh-organov (проверено 07.11.2018).

Капустина Н.В. 2008. Риски управления персоналом. - Экономика образования. № 4. С. 139-142.

Любичанковский С.В. 2008. Внутренний кризис системы управления: тектологический подход. - Общественные науки и современность. № 6. С. 53-59.

Магомедов К.О. 2017. Актуальные проблемы функиионирования и развития государственной гражданской службы Российской Федерации: материалы социологического исследования (октябрь 2016 - март 2017 г.). М.: Изд-во РАНХиГС. $40 \mathrm{c}$.

Митрофанова А.Е. 2013. Управление кадровыми рисками в работе с персоналом организации: автореф. дис. ... К.э.н. М. 28 с.

Потемкин В.К., Копейкин Г.К. 2012. Экономическая безопасность в системе управления персоналом: учебное пособие. 2-е изд., доп. СПб: Изд-во СПбГУЭФ. $123 \mathrm{c}$. 
Слободской А.Л. 2011. Риски в управлении персоналом: учебное пособие (под ред. В.К. Потемкина). СПб: Изд-во СПбГУЭФ. 155 с.

Цветкова И.И., Ботенко Т.А. 2016. Разработка методики оценки кадровых рисков. - Ученые записки Крымского федерального университета имени В.И. Вернадского. Экономика и управление. Т. 2(68). № 1. С. 256-262.

KAZAKOVA Noila Dokhievna, Dr.Sci. (Soc.), Professor of the Chair of Organizational and Personnel Work in Public Authorities, Institute of Economics and Law, Moscow State Institute of Radio Engineering, Electronics and Automation (Technical University) (20 Stromynka St, Moscow, Russia, 107996; kazaknelli@yandex.ru)

DENISOVA Zhanna Aleksandrovna, Cand.Sci. (Soc.), Associate Professor of the Chair of Organizational and Personnel Work in Public Authorities, Institute of Economics and Law, Moscow State Institute of Radio Engineering, Electronics and Automation (Technical University) (20 Stromynka St, Moscow, Russia, 107996; denisova@yandex.ru)

\title{
PERSONNEL RISKS IN HUMAN RESOURCE MANAGEMENT OF THE PUBLIC CIVIL SERVICE
}

\begin{abstract}
The article is devoted to the definition of the concept and identification of the features of personnel risks in the management of the civil service personnel. The authors carry out an analysis of a number of interpretations of personnel risk, characterize their shortcomings, and offer their own definition of personnel risks in personnel management of the public civil service. On the base of official data, the paper shows violations related, for example, to the non-settlement of the conflict of interest of federal and regional employees, holding public positions and other officials. However, the choice of personnel risks in the management of civil service personnel as a subject of research is of scientific and practical interest, primarily due to the high importance of this category of personnel in the enforcement of the powers of public authorities. The authors are convinced that corruption risks are types of personnel risks. However, in addition to the conflict of interests and corruption, the structure of personnel risks includes risks of unprofessionalism, negligence, irresponsibility, demotivation, professional burnout, etc., not related to the extraction of benefits. Ignoring these types of personnel risks leads to the fact that they more likely transforms into corruption.
\end{abstract}

Keywords: personnel risks, management of personnel of state civil service, categories of personnel of public authority 